\title{
FRF WAVE TEST BED AND BATHYMETRY INVERSION
}

\author{
Jane McKee Smith ${ }^{1}$, Spicer Bak ${ }^{2}$, Tyler Hesser ${ }^{1}$, Mary A. Bryant ${ }^{1}$, and Chris Massey ${ }^{1}$
}

\begin{abstract}
An automated Coastal Model Test Bed has been built for the US Army Corps of Engineers Field Research Facility to evaluate coastal numerical models. In October of 2015, the test bed was expanded during a multi-investigator experiment, called BathyDuck, to evaluate two bathymetry sources: traditional survey data and bathymetry generated through the cBathy inversion algorithm using Argus video measurements. Comparisons were made between simulations using the spectral wave model STWAVE with half-hourly cBathy bathymetry and the more temporally sparse surveyed bathymetry. The simulation results using cBathy bathymetry were relatively close to those using the surveyed bathymetry. The largest differences were at the shallowest gauges within $250 \mathrm{~m}$ of the coast, where wave model normalized root-mean-square was approximately twice are large using the cBathy bathymetry. The nearshore errors using the cBathy input were greatest during events with wave height greater than $2 \mathrm{~m}$. For this limited application, the Argus cBathy algorithm proved to be a suitable bathymetry input for nearshore wave modeling. cBathy bathymetry was easily incorporated into the modeling test bed and had the advantage of being updated on approximately the same temporal scale as the other model input conditions. cBathy has great potential for modeling applications where traditional surveys are sparse (seasonal or yearly).
\end{abstract}

Keywords: waves; test bed; Field Research Facility, wave modeling; STWAVE; bathymetry inversion, cBathy

\section{INTRODUCTION}

Near-coast wave models are generally validated with relatively small data sets that focus on analytical solutions, specialized experiments, or a few intense storms. While a few studies have compiled test beds that include several experiments or storms (e.g., Ris et al. 2002), these validation efforts are still limited in scope due to data availability. The US Army Corps of Engineers Field Research Facility (FRF) has a rich set of wave measurements from the depth of $26 \mathrm{~m}$ through the surf zone including the recently re-deployed cross-shore array. These data are recorded at various intervals, 24 hours a day, 365 days a year, which allows for the development of a Coastal Model Test Bed (CMTB) to validate wave models (and in the future circulation and morphology models). The CMTB utilizes these continuous data sources to evaluate model strengths and weaknesses to guide future research and development.

In addition to the requirement of applying forcing boundary conditions of winds, water levels, and offshore waves to drive nearshore wave models, accurate bathymetry is required to simulate wave transformation processes. At the FRF, highly accurate bathymetry data are collected with the Coastal Research Amphibious Buggy (CRAB) (Birkemeier and Mason 1984) using RTK GPS and the amphibious vehicle, Lighter, Amphibious, Resupply, Cargo (LARC) (Forte in prep.) using a single-beam acoustic sonar and RTK GPS (Figure 1). The FRF bathymetry surveys take many hours to complete, and are typically performed at a monthly interval. An Argus video system mounted on a tower at the FRF provides video-based imagery of the nearshore region (Holman and Stanley 2007). The Argus analysis software includes the cBathy algorithm that estimates bathymetry based on ocean wave celerity (Holman et al. 2013). The Argus system provides an alternate source of bathymetry (updated half hourly) in the most active morphological region, but the impact of applying cBathy-derived bathymetry as input to a wave model has not been evaluated. With surveys often being temporally sparse and difficult to make during high-wave events, cBathy is examined as a suitable compliment to traditionally measurement techniques.

The purpose of this paper is to describe spectral wave model simulations using the CMTB framework during the BathyDuck field experiment, 15-30 October 2015, applying both traditional bathymetric surveys and bathymetry estimated from Argus video observations using cBathy. The following section of the paper describes the FRF CMTB, including the FRF field measurements used for model evaluation and a brief overview of steady-state spectral wave model STWAVE. Then, the BathyDuck experiment is described, and a brief summary of the cBathy derived bathymetry is given. Next, the results of the wave model simulations using the more traditionally acquired, but temporally

${ }^{1}$ US Army Engineer Research and Development Center, Coastal and Hydraulics Laboratory, Vicksburg, MS 39180, USA

${ }^{2}$ US Army Engineer Research and Development Center, Coastal and Hydraulics Laboratory, Field Research Facility, Duck, NC 27949, USA 
sparse bathymetry data and the cBathy temporally-dense bathymetry applied within the FRF CMTB are provided. Lastly, conclusions and future work are discussed.

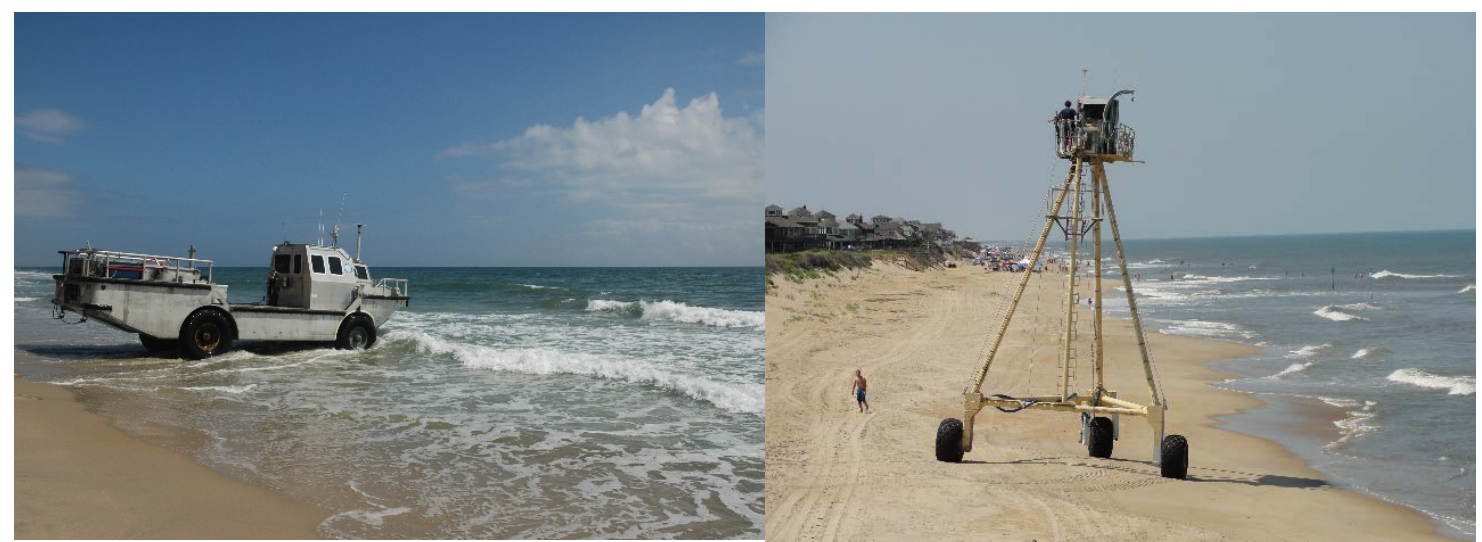

Figure 1. FRF Bathymetric Survey Vehicles LARC (left panel) and CRAB (right panel).

\section{FRF COASTAL MODEL TEST BED}

\section{FRF Measurements}

The FRF is located on the Atlantic Ocean near the town of Duck, on the Outer Banks of North Carolina, USA. Instruments at the FRF continuously measure waves, winds, water levels, and currents. Waves are measured at the FRF in depths of $26 \mathrm{~m}$ and $17 \mathrm{~m}$ with Waverider buoys; $11 \mathrm{~m}, 8 \mathrm{~m}, 6 \mathrm{~m}$, and $4.5 \mathrm{~m}$ with Acoustic Wave and Current profilers (AWAC); $3.5 \mathrm{~m}$ with an Acoustic Doppler Profiler; and four Paros pressure gauges with nominal depths ranging from $0-3 \mathrm{~m}$ mean sea level (MSL). Table 1 provides a summary of the cross-shore array of gauges. The shallowest gauges are in the active morphology evolution zone, and the depths change continually. A dune-mounted lidar is used to measure runup and wave statistics within the inner $100 \mathrm{~m}$ of the surf zone (Brodie et al. 2015). The FRF also has acoustic altimeters placed at three of the cross-shore array stations (Table 1). These instruments indicate bottom position from backscatter intensity profiles. Altimeter data are used to calculate burial depth of the two outer pressure sensors to correct for attenuation (Raubenheimer et al. 1998). The cross-shore array of gauges is approximately $400 \mathrm{~m}$ north of the 560-m-long FRF research pier.

\begin{tabular}{|c|c|c|c|c|c|}
\hline Gauge Type & $\begin{array}{l}\text { Nominal } \\
\text { Depth, } \mathrm{m}\end{array}$ & Measurement Type & Latitude & Longitude & $\begin{array}{l}\text { Sample } \\
\text { Frequency, } \mathrm{Hz}\end{array}$ \\
\hline Waverider & 26 & Directional wave & 36.25867 & -75.59217 & 1.28 \\
\hline Waverider & 17 & Directional wave & 36.20017 & -75.71533 & 1.28 \\
\hline AWAC & 11 & Directional wave and current & 36.18961 & -75.73940 & 2 \\
\hline AWAC & 8 & Directional wave and current & 36.18818 & -75.74323 & 2 \\
\hline AWAC & 6 & Directional wave and current & 36.18733 & -75.74654 & 2 \\
\hline AWAC & 4.5 & Directional wave and current & 36.18677 & -75.74871 & 2 \\
\hline Aquadopp & 3.5 & $\begin{array}{l}\text { Directional wave, current, and } \\
\text { bottom elevation }\end{array}$ & 36.18670 & -75.74898 & 2 \\
\hline Pressure - xp200 & 2.8 & Point wave and bottom elevation & 36.18621 & -75.75082 & 2 \\
\hline Pressure - xp150 & 2.1 & Point wave and bottom elevation & 36.18607 & -75.75135 & 2 \\
\hline Pressure - xp125 & 1.9 & Point wave & 36.18599 & -75.75162 & 2 \\
\hline Pressure $-x p 100$ & 0.75 & Point wave & 36.18593 & -75.75187 & 2 \\
\hline
\end{tabular}

The FRF CMTB is an automated system, developed in Python, that extracts data using web services to drive a wave model and evaluate the model performance with statistical comparisons to measurements. Waves are driven at the offshore boundary of the model domain with wave spectra from the 26-m buoy. Spatially constant winds and water levels are applied from winds and water levels measured at the end of the FRF pier. The water level measurements are from National Oceanic and Atmospheric Administration tide gauge 8651371, mounted to the seaward end of the FRF pier. Traditional bathymetric data are updated in the system as often as new bathymetry is available (typically monthly, 
but more often during the BathyDuck experiment). Bak et al. (2017) provides additional detail about the test bed structure.

\section{STWAVE Spectral Wave Model}

The FRF CMTB presently includes the US Army Corps of Engineers wave model STWAVE (Smith 2007, Massey et al 2011). STWAVE is a steady-state, phase-averaged spectral wave model for nearshore wave generation, propagation, transformation, and dissipation. Both the half- and full-plane versions of STWAVE are applied in the test bed. The STWAVE model domain is setup with parent simulations which then drive nested simulations. The parent grid was created from the FEMA Region 4 Floodplain Mapping Study (Blanton 2008) and is $17 \mathrm{~km}$ in the cross-shore and $38 \mathrm{~km}$ in the longshore with an offshore boundary at the $26 \mathrm{~m}$ water depth. The nested nearshore simulation utilizes temporally updated bathymetry based on FRF CRAB/LARC surveys. The updated nested grid construction process starts with the same background bathymetry as the parent grid and incorporates survey data based on inverse distance weighted interpolation. Bathymetry estimates from cBathy are likewise incorporated into the nested grid for the cBathy test bed simulations. The STWAVE parent grid is 345 cells in the cross-shore by 773 cells in the longshore, with a resolution of $50 \mathrm{~m}$ by $50 \mathrm{~m}$. The higher resolution nearshore nested grid is 100 cross-shore by 180 alongshore cells and $10 \mathrm{~m}$ by $10 \mathrm{~m}$ resolution. Figure 2 shows the domains for the parent and nested grids and the FRF gauge array location. Validation locations are focused on the FRF's cross-shore array of wave gauges described in Table 1. For the purposes of discussion, gauges are referred to by a combination of nominal depth and gauge type (e.g., AWAC-6m) or the cross-shore location (e.g., xp200m).

\section{Statistics}

To evaluate STWAVE performance, bulk statistics are calculated from the observed and wave model output spectra. These bulk statistics are compared using the following metrics:

\section{Residual}

$$
\mathrm{R}=\mathrm{i}_{\bmod }-\mathrm{j}_{\mathrm{obs}}
$$

where $i_{\text {mod }}$ and $j_{\text {obs }}$ are the individual time matched observation and model output, respectively. The residual is the difference between the model and observations.

\section{Bias}

$$
b=\frac{1}{N} \sum i_{\text {mod }}-j_{o b s}
$$

The bias represents an assessment of the overall mean of the model error.

\section{Normalized Root-Mean-Square Error (NRMSE)}

$$
N R M S E=\sqrt{\frac{\sum\left(i_{\text {mod }}-j_{o b s}\right)^{2}}{\sum j_{o b s}^{2}}}
$$

NRMSE assesses the scatter in the model output, normalized by the magnitude of the observation. This is otherwise known as percent root-mean-square error. 


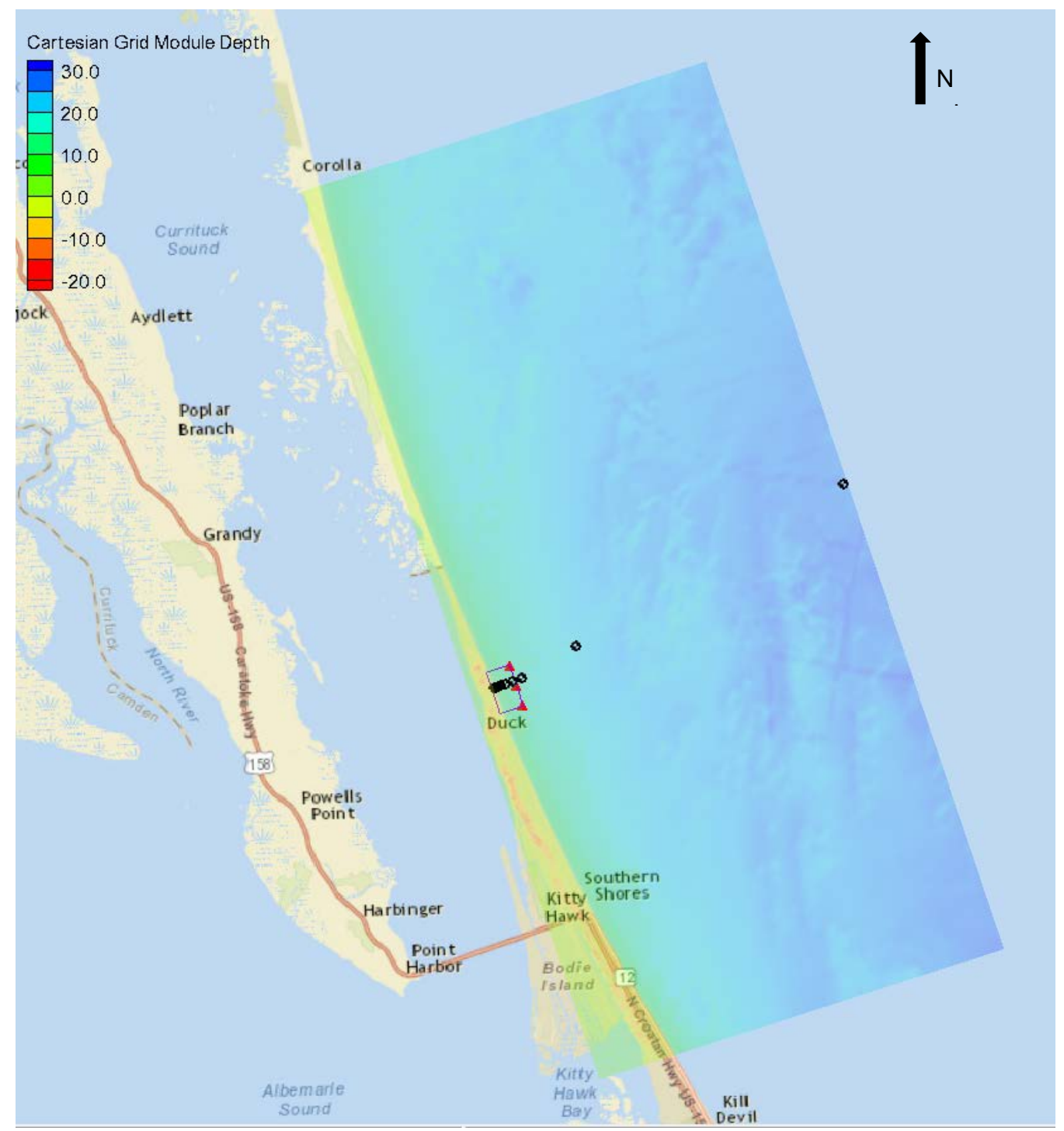

Figure 2. Parent and nested grid domains. The cross-shore wave gauge array is shown as black circles, and the red triangles indicate forcing points for the nested grid.

\section{BATHYDUCK EXPERIMENT DESCRIPTION}

The BathyDuck field experiment was designed with the focus of evaluating bathymetry inversion techniques at the FRF during the fall of 2015. Between 15 and 30 October 2015, bathymetry surveys were performed as frequently as possible (Table 2). The goal of the experiment was to create a field dataset of remotely sensed estimates of bathymetry and high-spatial/temporal in-situ sampling of environmental conditions and bathymetry. During this time period, which followed the passing of Hurricane Joaquin, the wave heights ranged from $0.4 \mathrm{~m}$ to $2.4 \mathrm{~m}$ with a mean peak wave period of $8 \mathrm{~s}$.

As part of the experiment, a series of bathymetric surveys were taken using a combination of the CRAB and the LARC platforms. Prior to the experiment a full survey of the entire FRF property was collected with an alongshore line spacing of $50 \mathrm{~m}$, then during the experiment surveys were focused on the north side of the pier near the gauge array. These survey lines were spaced at $25 \mathrm{~m}$. The dates and locations of the surveys are shown in the Table 2. The alongshore survey bounds in Table 2 are relative to the shoreline-relative FRF coordinate system, as shown in Figure 3. Bathymetry data were then gridded to a 12-m cross-shore by 24-m alongshore grid using a Kriging algorithm with a search ellipse of $20 \mathrm{~m}$ in the cross-shore and $75 \mathrm{~m}$ in the alongshore direction and a linear variogram (slope: 1, anisotropy ratio: 2). 


\begin{tabular}{|l|l|l|}
\hline \multicolumn{4}{|l|}{ Table 2. BathyDuck survey sates and alongshore extents. } \\
\hline Date & Vehicle & FRF Alongshore Bounds, $\mathrm{m}$ \\
\hline 14 October 2015 & LARC & $0-1102$ \\
\hline 19 October 2015 & CRAB & $570-985$ \\
\hline 21 October 2015 & LARC & $526-1108$ \\
\hline 23 October 2015 & CRAB & $569-887$ \\
\hline 30 October 2015 & CRAB & $661-985$ \\
\hline
\end{tabular}

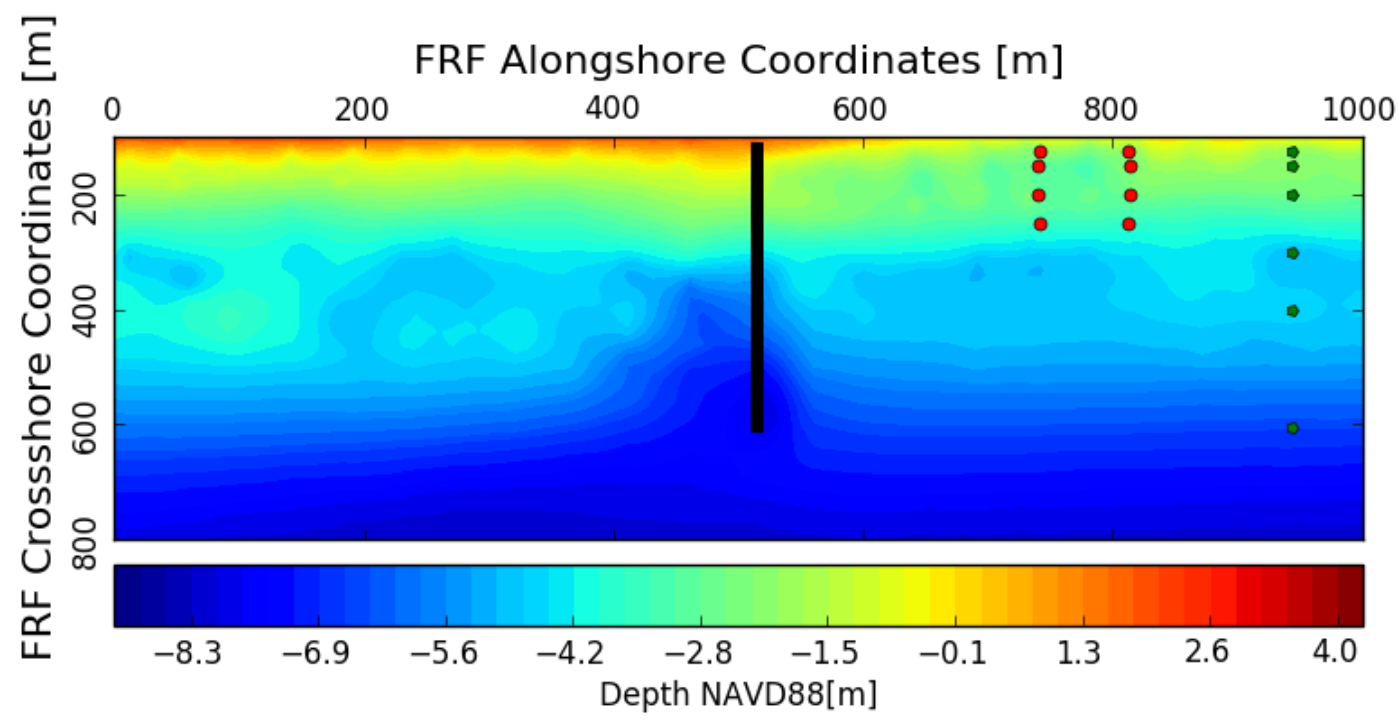

Figure 3. BathyDuck nearshore instrumentation locations: green gauges are part of the FRF's cross-shore array of wave gauges, red dots are the location of temporarily installed instrumentation.

\section{cBathy Bathymetry}

The cBathy bathymetry inversion algorithm (Holman et al. 2013) calculates incident wave speeds from the video imagery and inverts those wave speeds to bathymetry estimates in the nearshore using the linear dispersion relationship and applying a Kalman filter. The Kalman filter adds robustness to the algorithm, providing answers in rain, clouds and even when a camera goes down for a short period of time. Holman et al. (2013) evaluated the root-mean-square error and bias of cBathy derived bathymetry to be $0.19 \mathrm{~m}$ and $0.51 \mathrm{~m}$, respectively, for significant wave heights less than $1.5 \mathrm{~m}$. Figure 4 shows a comparison between the measured bathymetry and three cBathy bathymetry estimates during the BathyDuck experiment. The left panel of the figure shows the measured bathymetry from 14 October 2015. The next panel to the right is a cBathy bathymetry estimate from approximately the same time the bathymetry survey was completed (times are in UTC). Two more cBathy bathymetry estimates are shown in the plot for 16 October 2015 and 18 October 2015.

Comparing the two time matched bathymetries (left two panels), many features are similar; the shore attached bar is present in both panels at approximately $800 \mathrm{~m}$ in the alongshore, the sand bar is of comparable depth, and there are similarly shaped features on either side of the FRF pier (marked as a black line in the figure). While there are similarities in the bathymetries, there are also differences, mainly at the southerly end of the FRF property. The shore oblique trough present in the measured bathymetry (approximately 200 - 300 m alongshore) is markedly different in the cBathy estimate. As the cBathy bathymetric estimations evolve, on the north side of the pier, the trough (at approximately $700 \mathrm{~m}$ ) 
grows and evolves to cut through the sand bar, reducing spatial extents of the bar feature just north of the pier. It is the evolution of these and similar features that are expected to modify the wave field between surveys.
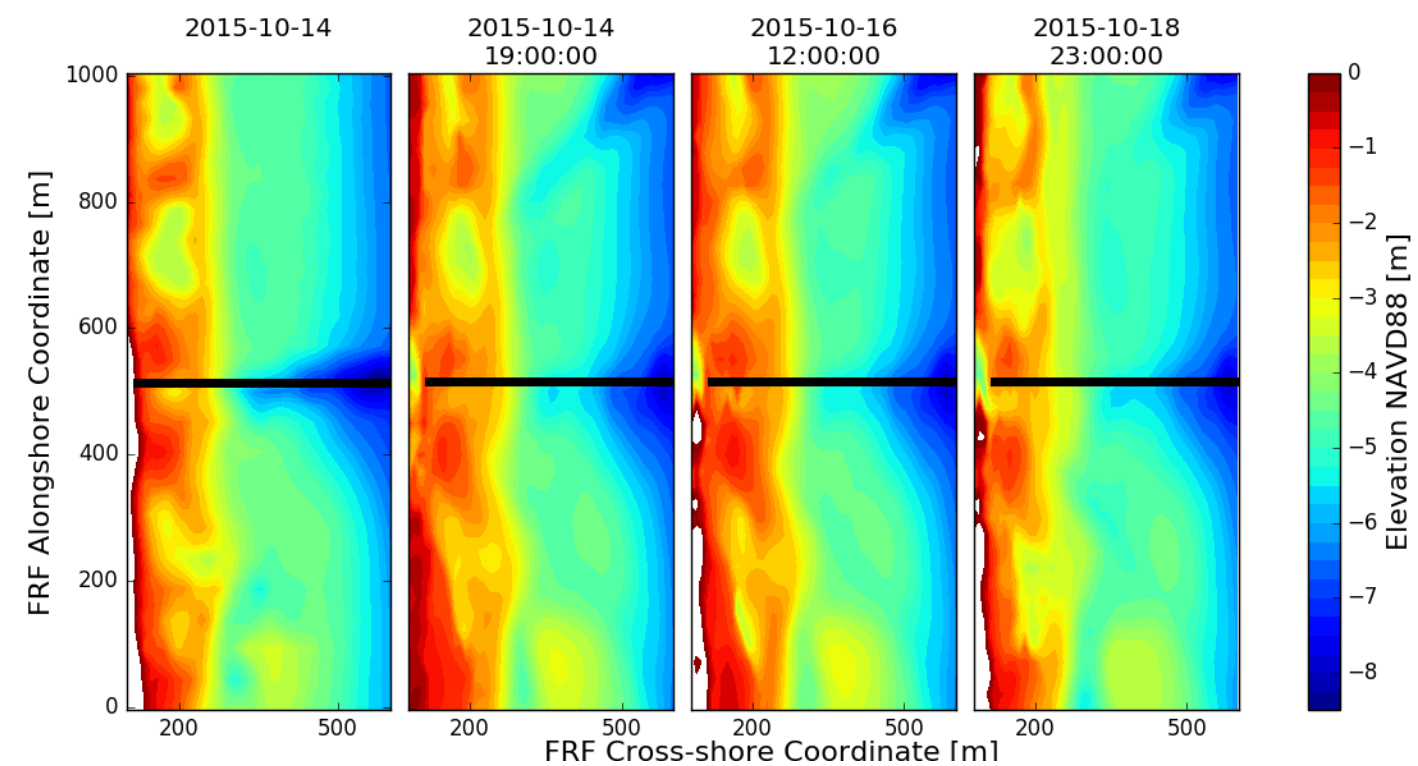

Figure 4. Comparison plot between measured and cBathy bathymetry. The left subplot is the measured bathymetry from a FRF survey, while the three right plots are from cBathy with collections at denoted time.

On the upper right in all panels of the cBathy estimates in Figure 4 (right three panels) there is a diagonal feature coincident with the seam between Argus cameras. This prominent camera seam affect (Bergsma et al., 2016) can be seen in the offshore region between 800 and $1000 \mathrm{~m}$ in the alongshore. The seam affect is due to latency or rectification issues between the two cameras causing over estimations of the depth where the two camera images are brought together. The effect of the camera seam on the simulations is discussed in the Results section.

\section{Simulations}

The first set of simulations utilize the surveyed bathymetries listed in the BathyDuck Experiment Description section. For each new survey, the data were ingested into the CMTB. The most recent gridded data were interpolated onto the background grid, and the CMTB automatically updated the bathymetry to produce the model grids for the duration of the study. Simulations using the surveyed bathymetry are referred to as measured sims. The second set of simulations, referred to as cBathy sims, utilize the Kalman filtered cBathy depth estimates (updated every 30 min during daylight). The cBathy bathymetry was ingested into the CMTB in a similar manner to the measured sims, it was interpolated to the background grid, and the model was initialized with the time matched cBathy estimate.

As part of the incorporation into the FRF CMTB, both the FRF gridded product and half hourly cBathy output from Argus were converted into netCDF file format. These data were then stored on a THREDDS server for quick aggregation of time dimensioned data, allowing for easy ingestion of multiple data types and sources into the CMTB for model setup and comparison. All data compared are time matched to the observation data.

\section{RESULTS}

The BathyDuck experiment provided an ideal window to evaluate STWAVE model performance. STWAVE simulations were set up and run using the two different types of bathymetry input: traditional CRAB/LARC surveys using acoustic sonar and Argus video-based estimates applying the cBathy algorithm. Significant wave height skill statistics of bias and normalized root-mean-square error for the BathyDuck time period are presented for the nearshore gauge array starting at the 11-m AWAC in Figure 5. The overall difference in errors between model applications using the two different bathymetries is fairly small, with the largest $\mathrm{H}_{\mathrm{s}}$ bias of approximately $15 \mathrm{~cm}$ at the gauge nearest to the shoreline (approximately 25 meters from the shore). Both sets of simulations are biased slightly high at 
the 8-m and 6-m AWACs $(5-10 \mathrm{~cm})$, but bias becomes negative (underestimation) at the shallowest gauges. Bias in the cBathy sims is about twice that of the measured sims at the shallowest gauges.
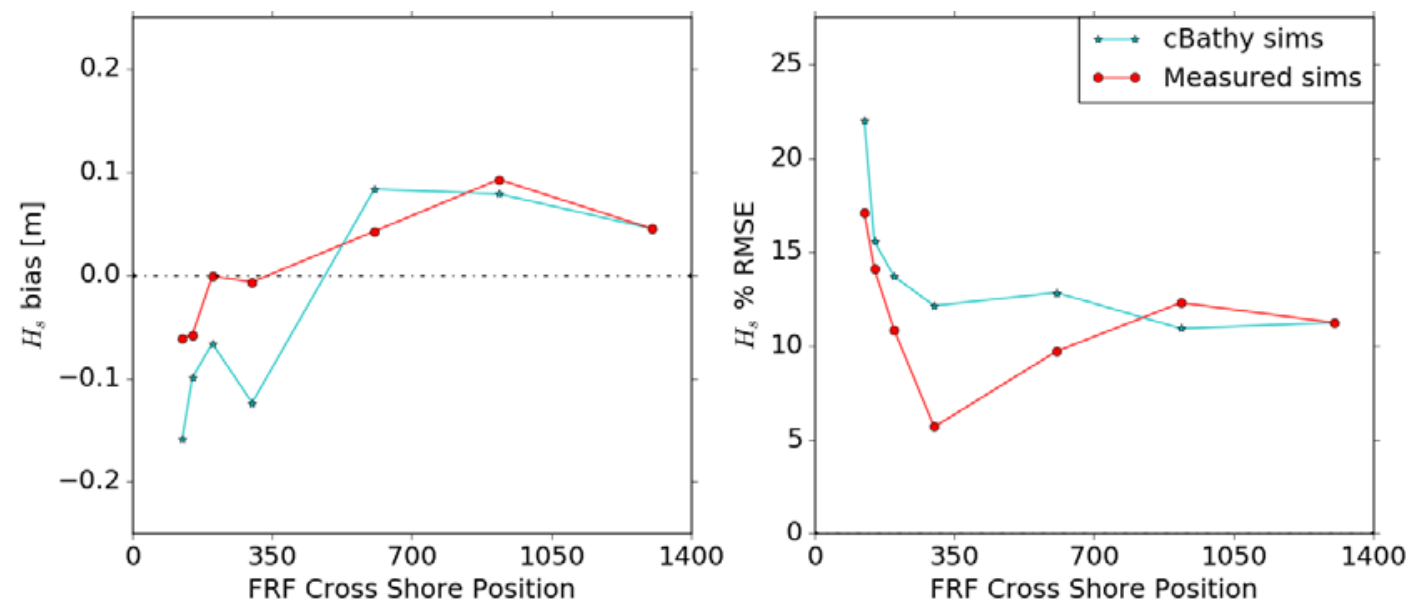

Figure 5. Cross shore statistics from comparison between measured sims and cBathy sims.

The NRMSE in the two simulations is likewise similar seaward of $700 \mathrm{~m}$ (600 m offshore) at 10\%. Errors increase in the cBathy simulations between $700 \mathrm{~m}$ and approximately $200 \mathrm{~m}$ while the measured bathymetry simulations errors decrease to about 5\%. This is the region where the cBathy algorithm affects the most change in bottom position. Inshore of $200 \mathrm{~m}$, the wave model produces higher values of NRMSE for both simulations. Both simulations have greater NRMSE in the very nearshore region (NRMSE increases to 17 and 22\% for the measured and cBathy sims, respectively).

The upper panel of Figure 6 shows the time history of significant wave height at the 6-m AWAC (red dots, $\sim 600 \mathrm{~m}$ in the FRF cross-shore coordinate) and at the offshore model boundary (green line). The lower panel compares the wave height errors (residuals) for the measured and cBathy sims at the 6-m AWAC location. The differences between cBathy and measured simulations residuals are fairly minimal, as might be expected given that the sea-floor elevation did not change much in this area. The scatter plot in the right panel shows good correlation between both simulations and the 6-m AWAC observations, with the cBathy sims being slightly more biased higher than the measured sims, as also seen in Figure 6. The largest errors in wave height for both simulations occur when the wave heights are the highest and where the local wave height differs the most from offshore buoy (under goes the greatest transformation) (e.g., early on 19 October).

Figure 7 shows similar plots at the FRF cross-shore coordinate of $200 \mathrm{~m}$ to provide a better understanding of how the evolution of the cBathy bathymetry affects the nearshore wave field. First, note that the nearshore observations show a strong variation with the tide compared to the offshore measurements. Wave heights are significantly reduced due to depth-limited wave breaking (compare to Figure 6). Overall, the wave height residual, plotted in the bottom panel of Figure 7, for the two sets of simulations behave similarly, except for the large negative residuals for the cBathy sims on 27 October, when the wave heights are large (over $2 \mathrm{~m}$ offshore). This is also shown as scatter below the perfect agreement line in the panel shown at the right of Figure 7 (further evidenced by the increased NRMSE values for cBathy sims, shown in Figure 5). 


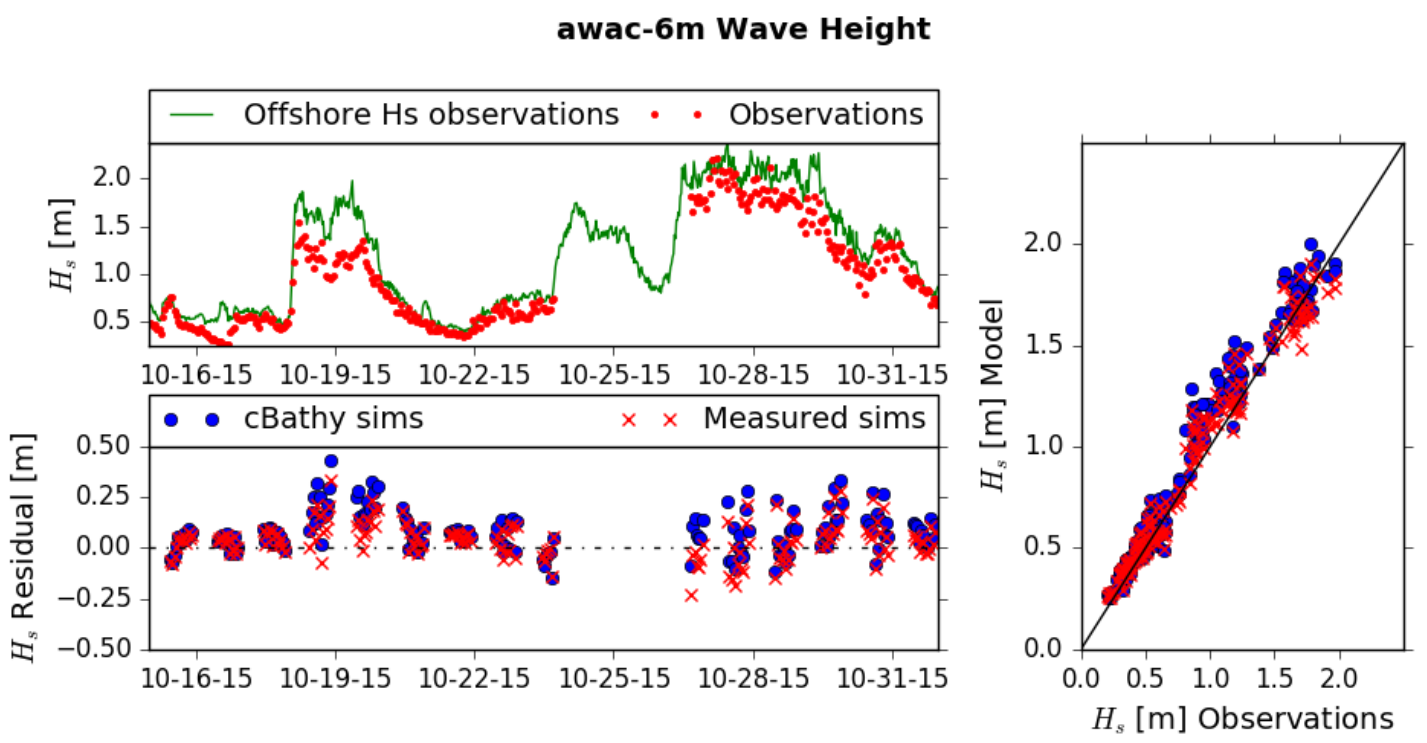

Figure 6. Time-series plot of the comparison between cBathy sims and measured sims at nominal 6-m water depth.

\section{xp200m Wave Height}

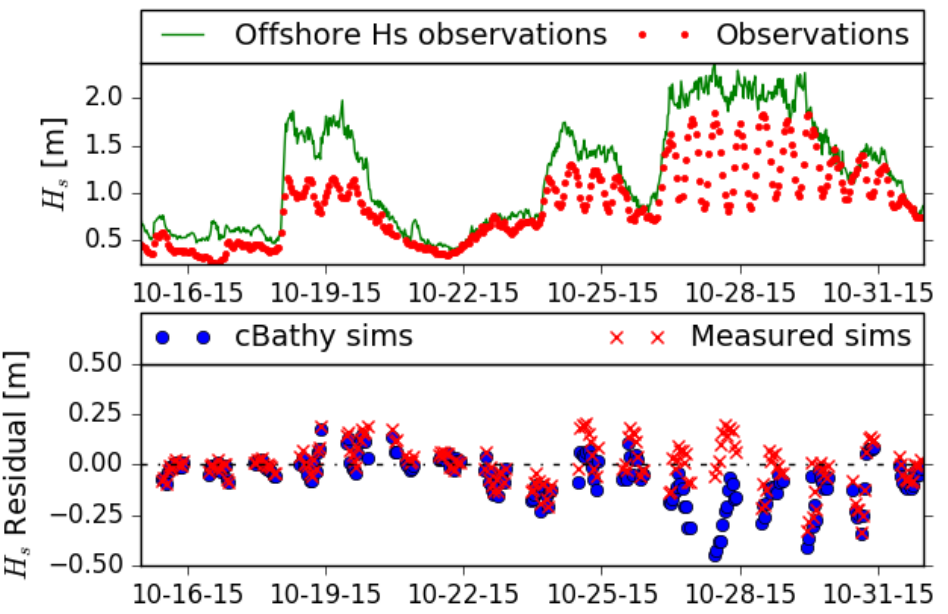

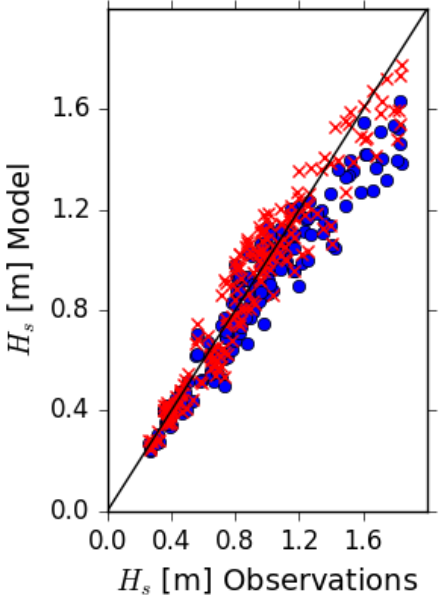

Figure 7. Time series plot at the 200-m cross shore location (in a local coordinate system).

To better understand why the measured and cBathy sims respond differently at the same point in time, we examine the wave height and instantaneous bathymetries for two time periods. First, we examine a time when the simulations respond similarly. Figure 8 shows the wave heights and bathymetry profiles in the top and bottom plots, respectively, at the FRF's cross-shore array of wave gauges. Offshore at the 26-m Waverider, estimates for wave height are approximately $0.45 \mathrm{~m}\left(\mathrm{~T}_{\mathrm{p}}=8 \mathrm{~s}\right)$ while in the nearshore the wave height predictions from both sets of simulations range between 0.4 and $0.45 \mathrm{~m}$ before wave breaking is initiated. The measured bathymetry used in this comparison is one day old, and the surveyed and cBathy bathymetries used in the simulations are similar (lower panel). The sand bar is slightly more shoreward and larger in the cBathy bathymetry. The effects of the camera seam, as documented by Bergsma et al. (2016), can be seen in the bottom of Figure 8 at approximately $550 \mathrm{~m}$ in the cross-shore coordinate, and this in turn has a small effect on the wave height profile. 
Wave height \& Bathymetry at Oct-15-2015 22:00:00
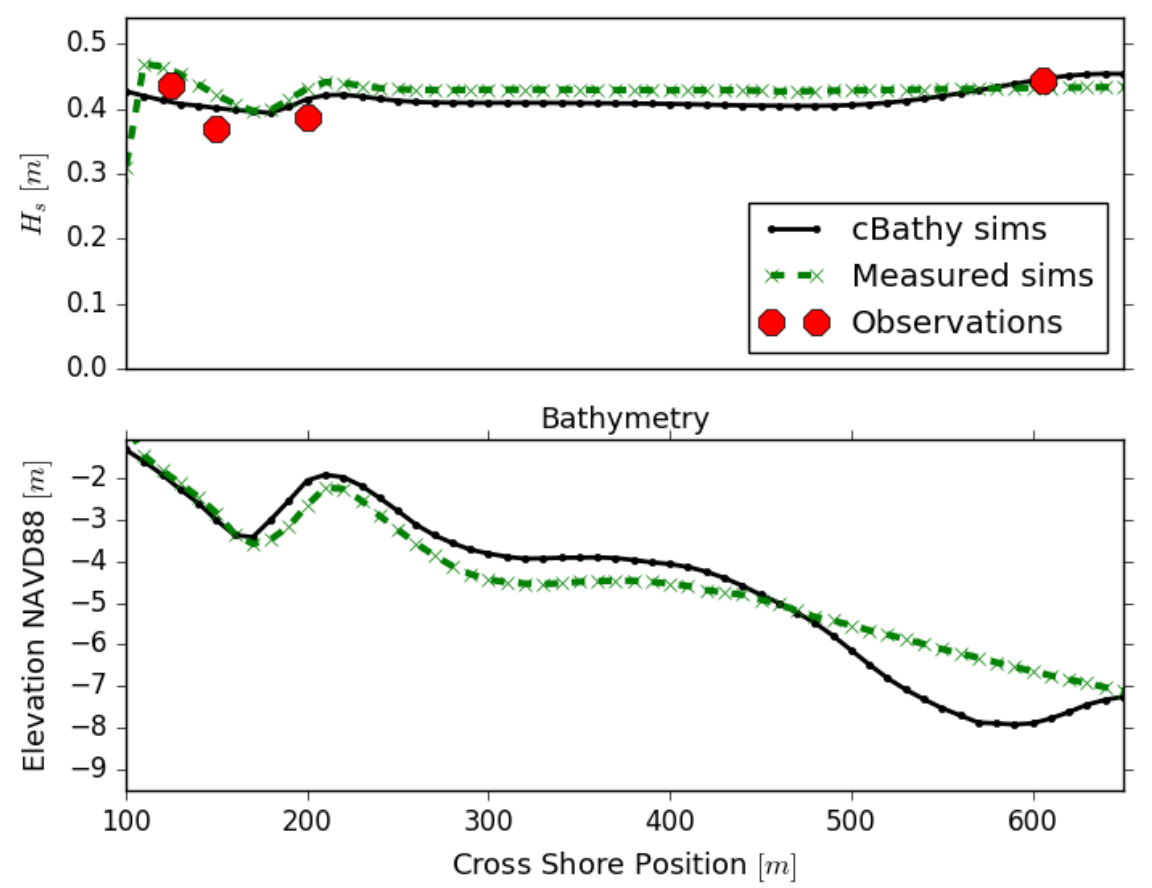

Figure 8. Wave height and bathymetry example in which the wave heights predicted using the cBathy estimated bathymetry were similar in error to those using the measured bathymetries.

Figure 9 shows an example of the wave predictions from the cBathy sims that are significantly different from the measured sims. This is during the period of relative poor performance seen in Figure 7 on 27 October. The offshore wave height estimates at the 26 - $\mathrm{m}$ Waverider were $2.11 \mathrm{~m}\left(\mathrm{~T}_{\mathrm{p}}=6 \mathrm{~s}\right)$, and the nearshore wave height predictions in both models range between 1.5 and $1.8 \mathrm{~m}$ before breaking. The sandbar and trough from the cBathy bathymetry are very pronounced and slightly shoreward compared to the surveyed bathymetry. Also, cBathy produces another, small bar feature between $300 \mathrm{~m}$ and $400 \mathrm{~m}$ in the FRF coordinate system, and the camera seam effect is again seen as a trough between 500 and $600 \mathrm{~m}$. The larger cBathy produced bar in the nearshore degrades the cBathy results, producing an overestimation of depth-limited breaking. The on-shore bar movement shown by cBathy is counterintuitive during this time of increasing wave height. Figure 9 shows the sensitivity of nearshore wave model results to relatively small changes in surf zone bathymetry.

The camera seam effect in cBathy was illustrated along the cross-shore gauge profile in Figures 8 and 9. In the two-dimension wave height field, the over estimation of depth due to the Argus camera seams (see Figure 4) causes wave focusing to the south of this feature in the simulations using the cBathy bathymetry. Figure 10 shows the two-dimensional STWAVE wave height field for the CRAB/LARC bathymetry and cBathy simulations on 15 October at 2200 hrs UTC. In the cBathy simulation (right panel), a streak of larger wave heights is visible radiating from the offshore boundary at a roughly 45 degree angle toward the base of the pier, which does not exist in the simulations using the CRAB/LARC bathymetry. This issue is currently being addressed and will be fixed in the near-term. 
Wave height \& Bathymetry at Oct-27-2015 13:00:00
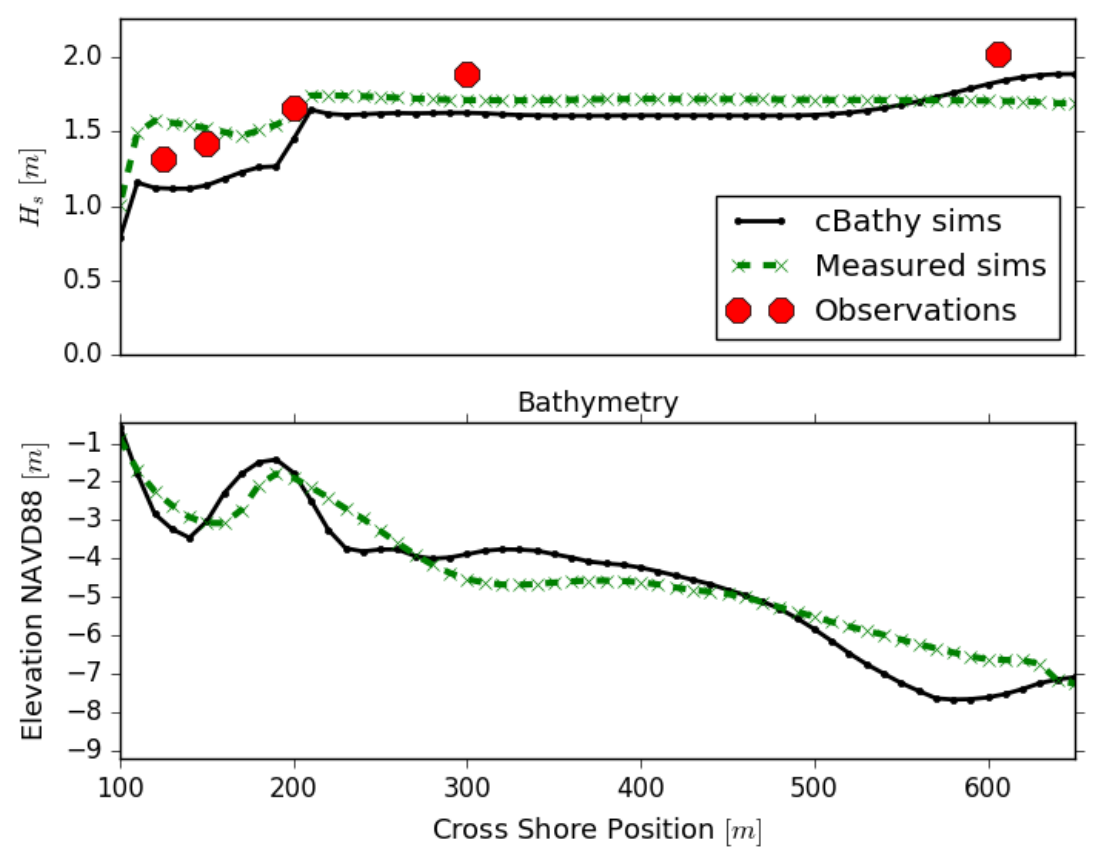

Figure 9. Wave height and bathymetry example in which wave height estimates along the FRF's cross-shore array respond poorly while using cBathy bathymetry estimates.

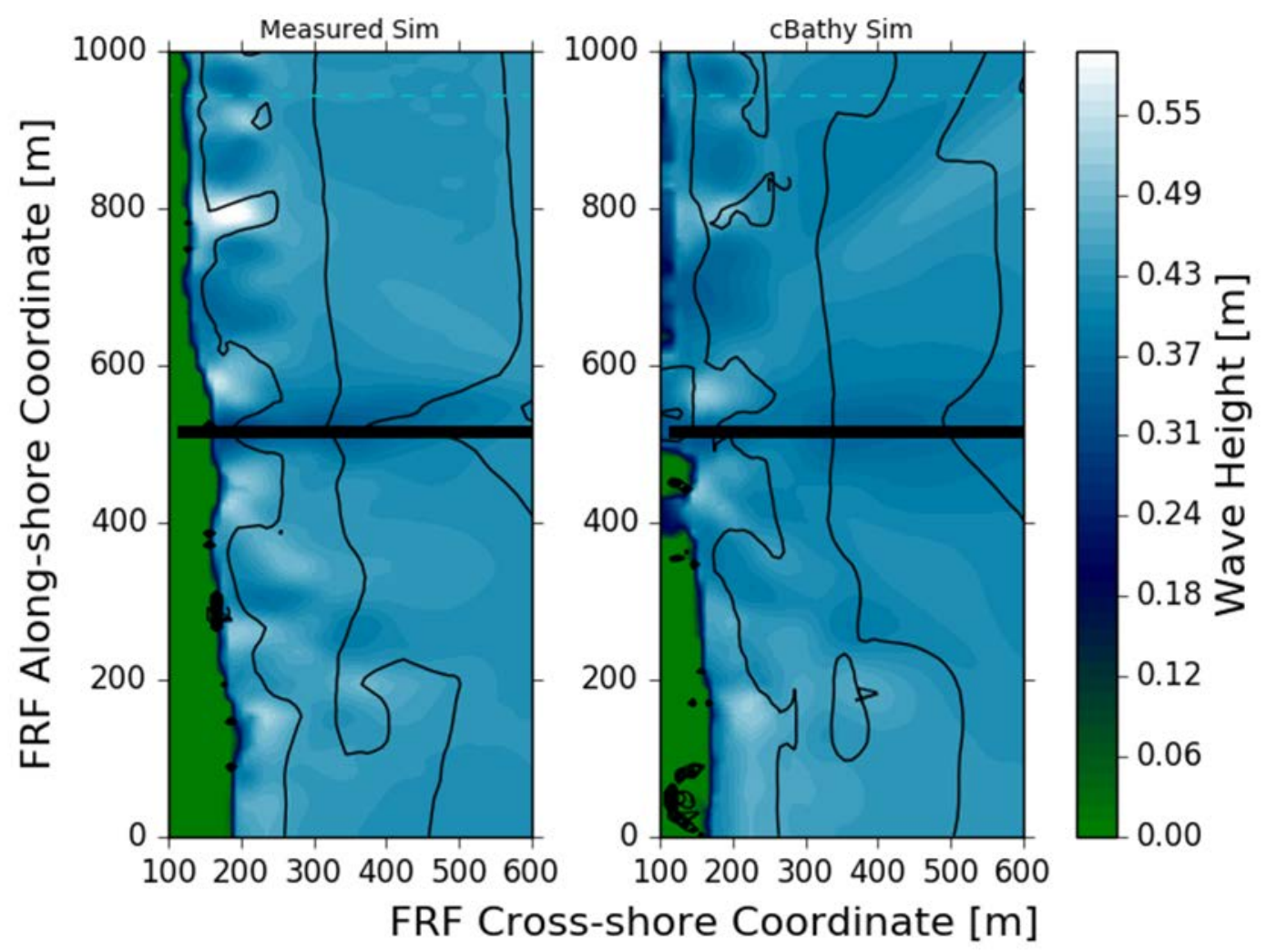

Figure 10. Comparison of the spatial wave height field during 15 October at 2200 UTC. 


\section{CONCLUSIONS}

An automated Coastal Model Test Bed has been built for the FRF to evaluate coastal models. The system takes advantage of a wealth of wave, wind, and water levels measurements routinely collected at the FRF. For the BathyDuck experiment in October of 2015, the FRF CMTB was expanded to evaluate bathymetry input using two sources of data: traditional survey data collected with acoustic methods using the CRAB or LARC and bathymetry generated through the cBathy inversion algorithm using video measurements. Comparisons were made between STWAVE simulations using the frequently-updated cBathy bathymetry and the more temporally sparse surveyed bathymetry. The simulations using cBathy bathymetry compared well with those using the surveyed bathymetry. The largest differences were at the shallowest gauges within $250 \mathrm{~m}$ of the shoreline, where biases were about twice as large $(5-15 \mathrm{~cm})$ using cBathy bathymetry and NRMSE was about 50\% larger (12-22\%). The nearshore errors using the cBathy input were greatest during high wave events ( $>2 \mathrm{~m}$ offshore wave heights).

For this limited application, the Argus cBathy algorithm proved to be a suitable bathymetry input for the nearshore wave model, STWAVE. Although the model errors were larger than using the highquality CRAB/LARC bathymetry, cBathy bathymetry was easily incorporated into the modeling procedure and had the advantage of being updated on approximately the same temporal scale as the other model input conditions (offshore waves, winds, and water levels). Deploying an Argus station is less expensive, safer, and requires less man power than that of traditional bathymetry measurement techniques. The real potential advantage of cBathy will be applications where traditional surveys are sparse (seasonal or yearly). Follow-on analysis will evaluate modeling results on these longer time scales. Additional work is ongoing to evaluating cBathy using both traditional surveys and stationary sonic gauges. Improvements to the cBathy algorithm and removal of the camera seam effect will benefit FRF CMTB use of cBathy as an input.

\section{ACKNOWLEDGEMENTS}

Permission to publish this paper was granted by the Chief of Engineers, US Army Corps of Engineers (USACE). Funding for this work was provided by the USACE Coastal Observation and Data Systems Program. Program Manager was Jeff Waters, and Technical Director was Jeff Lillycrop.

\section{REFERENCES}

Bak, S., J.M. Smith, T. Hesser, and M.A. Bryant. 2017. Initialization and setup of the costal model test bed: STWAVE, ERDC/CHL CHETN-I-93. Vicksburg, MS; U.S. Army ERDC. http://dx.doi.org/10.21079/11681/21463.

Bergsma, E.W.J., D.C. Conley, M.A. Davidson, and T.J. O’Hare. 2016. Video-based nearshore bathymetry estimation in macro-tidal environments, Mar. Geol. 274, 31-41. Doi: 10.1016/j.margeo.2016.02.001

Birkemeier, W.A., and C. Mason. 1984. The Crab: A Unique Nearshore Surveying Vehicle. J. Surv. Eng.-ASCE, 110(1), 1-7.

Blanton, B. 2008. Report for the State of North Carolina floodplan mapping project: Coastal flood analysis system. RENCI Technical Report TR-08-8. Chapel Hill, NC: Renaissance Computing Institute. http://www.renci.org/wp-content/uploads/2014/03/TR-08-08-small.pdf

Brodie, K.L., B. Raubenheimer, S. Elgar, R.K. Slocum, and J.E. McNinch. 2015. Lidar and pressure measurements of inner-surfzone waves and setup. J. Atmos. Ocean. Tech., 32(10):1945-1959.

Forte M.F., W.A. Birkemeier, and R.J. Mitchell. In prep. Nearshore Survey System Evaluation. ERDC TR-17-xx, Vicksburg, MS.

Holman, R., N. Plant, and T. Holland. 2013. cBathy: A robust algorithm for estimating nearshore bathymetry. J. Geophys. Res., 118(5), 2595-2609.

Holman, R.A., and J. Stanley. 2007. The history and technical capabilities of Argus. Coast. Eng., 54(67), 477-491.

Massey, T., M. E. Anderson, J. M. Smith, J. Gomez, and R. Jones. 2011. STWAVE: Steady-State Spectral Wave model user's manual for STWAVE, Version 6.0. ERDC/CHL SR-11-1. Vicksburg, MS; U.S. Army ERDC. http://acwc.sdp.sirsi.net/client/search/asset/1005242.

Raubenheimer, B., S. Elgar, and R.T. Guza. 1998. Estimating Wave Heights from Pressure Measurements in Sand Bed, J. Waterw. Port C.-ASCE, 124(3).

Ris, R., L. Holthuijsen, J.M. Smith, N. Booij, and A. Van Dongeren. 2002. The ONR test bed for coastal and oceanic wave models. Proc., 28th International Conference on Coastal Engineering, 380-391.

Smith, J.M. 2007. Full-plane STWAVE with bottom friction: II model overview. ERDC TN-SWWRP07-5; ERDC/CHL CHETN-I-75.Vicksburg, MS. 